\title{
Topographic and Chemical Analysis of Reciprocating and Rotary Instruments Surface after Continuous Use
}

\author{
Mariana Mena Barreto Bastos', Aida Rene Assayag Hanan', Ana Mena \\ Barreto Bastos ${ }^{2}$, André Augusto Franco Marques ${ }^{3}$, Lucas da Fonseca Roberti \\ Garcia ${ }^{4}$ Emílio Carlos Sponchiado-Júnior ${ }^{1}$
}

'School of Dentistry, UFAM

- Universidade Federal do

Amazonas, Manaus, AM, Brazil

2IFAM - Instituto Federal do

Amazonas, Manaus, AM, Brazil ${ }^{3}$ Higher School of Health Sciences, UEA - Universidade do Estado do Amazonas, Manaus, AM, Brazil ${ }^{4}$ Department of Dentistry, Endodontics Division, Health Sciences Center, UFSC - Universidade Federal de Santa Catarina, Florianópolis, SC, Brazil

Correspondence: Dr. Lucas da Fonseca Roberti Garcia, Avenida Madre Benvenuta, $\mathrm{n}^{\circ} 388$, apto. 713, 88036-500 Florianópolis, SC, Brasil. Tel: +55-48-3721-5843. e-mail: drlucas.garcia@gmail.com

Key Words: endodontics; root canal preparation; reciprocating motion; chemical analysis.

\section{Introduction}

The development of new instruments, such as those made from nickel-titanium (NiTi) alloy, has been essential for the enhancement of root canal preparation techniques, making them faster and more efficient to perform (1). Among the characteristics of these instruments, flexibility, cyclic fatigue and torsional resistance are the most important, as they allow safer biomechanical preparation of canals with accentuated curvature $(2,3)$. However, different manufacturing strategies have been proposed even now to improve mechanical properties, by reducing risks of fracture and increasing the useful life of NiTi instruments (4).

Among the new manufacturing strategies, thermomechanical treatment of conventional NiTi alloy led to the M-Wire alloys (5). Instruments manufactured using this new technology have superelasticity, and greater flexibility and cyclic fatigue resistance than conventional NiTi instruments $(5,6)$. The superelasticity is associated to transformation of the alloy martensitic phase into austenitic when submitted to stress, followed by spontaneous reversion to martensitic phase after stress release, making the instrument recover its original shape $(4,5)$.

The mechanical properties of M-Wire alloy allowed development of systems for root canal preparation that use a single file, as the reciprocating instruments $(2,6)$. Recently, a rotary system that also use a reduced number of instruments - ProTaper Next system (Dentsply/Maillefer, Ballaigues, Switzerland) - manufactured in M-Wire alloy was introduced into the market $(2,6)$. This system was developed with the purpose of simplifying preparation, by reducing the number of instruments and consequently the number of operative steps (6). However, manufacturers have recommended their use to a maximum of three or four canals in the same patient. Constant reuse of instruments manufactured in M-Wire leads to wear and deformation, increasing the risk of fracture during preparation $(3,7)$.

There are few studies that evaluated the topographic and chemical changes that occur on these instrument's surface after their repeated use $(3,7)$. Therefore, the aim of this study was to evaluate the changes in surface characteristics and chemical composition of NiTi alloy of reciprocating and rotary instruments before and after continuous use. The NiTi content on the instruments surface before and after root canal preparation was also quantified.

\section{Materials and Methods Collection of Instruments}

In this study thirty brand-new instruments of the following systems were used: ProTaper Next (Dentsply/ Maillefer, Ballaigues, Switzerland) (Batches \#1183247, 1190349 and 1138556) and WaveOne (Dentsply/Maillefer) 
(Batches \# 1067705 and 1048300). Sixty simulated root canals (IM do Brasil Ltda., São Paulo, SP, Brazil), fabricated in transparent polyester resin blocks were prepared with these instruments. The simulated canals had a length of $16 \mathrm{~mm}$; curvature radius of $3 \mathrm{~mm}$, and angle of curvature of $30^{\circ}$.

Initially, the instruments were removed from their packaging materials, and randomly distributed into 3 groups $(n=10)$, using the Random Sequence Generator program, as follows: PNX1 Group - ProTaper Next system - instrument X1 (17.04); PNX2 Group - ProTaper Next system - instrument X2 (25.06) and WO Group - WaveOne system - Primary instrument (25.08v). No previous cleaning treatment was performed on the instruments, as they were sterile.

\section{Scanning Electron Microscopy (SEM) and Chemical} Analysis by Energy-Dispersive Spectroscopy (EDS)

The instruments were fixed on metal stubs for initial analysis of their topography by scanning electron microscopy (SEM) (Quanta 250, FEI Co., Hillsboro, OR, USA) in environmental mode. Image acquisitions were performed on both sides of the active part of the instruments. The micrographs of the active part of instruments were analyzed in three distinct points: active tip of the instrument, 2 $\mathrm{mm}$ and $4 \mathrm{~mm}$ short of the active tip, at 250 and 500 $X$ magnifications, in a blind manner, by two previously calibrated observers (0.88 and 0.90 - Kappa test).

The NiTi content (wt \%) on the instruments surface before their use was also analyzed, by using an energy dispersive spectrometer (EDS) (EDAX - AMETEK, Inc., Mahwah, NJ, USA). Only the active part of the instruments was considered for the analysis by EDS, because this is the portion of the instrument that presents most deformations after use (3).

\section{Simulated Root Canal Preparation}

The working length was determined with the aid of a size $10 \mathrm{~K}$-type file (Dentsply/Maillefer), that was inserted into the simulated canal in the apical direction, until its tip could be visualized at the end of the canal. After this, the instrument was withdrawn to $1 \mathrm{~mm}$ short of the obtained length, determining the working length $(15 \mathrm{~mm})$.

All the instruments were used in a 6:1 reduction contraangle (Dentsply/Maillefer), powered by an electric motor (Motor X-Smart Plus, Dentsply/Maillefer), at the setting previously defined for each system.

The simulated canals in PNX1 Group were prepared with the ProTaper Next system, according to the manufacturer's recommendations. Initially, the canal was negotiated with a size 10 K-type file. Subsequently, instrument X1 (17.04) was used up to the working length. Following the sequence recommended by the manufacturer, instrument X2 (25.06) was used at the working length for apical finishing, thus, establishing PNX2 Group. The instruments were introduced into the canal in small $(3 \mathrm{~mm}$ ) back-and-forth movements, without completely removing them from the canal. After every $3 \mathrm{~mm}$ advance into the simulated canal, the instruments were removed to clean the active part with sterile gauze.

The simulated canals in WO Group were prepared with the WaveOne system according to the manufacturer's recommendations. As described in the previous groups, the canal was initially negotiated with a size $10 \mathrm{~K}$-type file. Subsequently, the simulated canal was prepared with the Primary 25.08 instrument at the working length. The instrument was introduced into the canal in small $(3 \mathrm{~mm})$ back-and-forth pecking movements. The instruments were cleaned in the same way as described for Groups PNX1 and PNX2.

Every time after the instruments were introduced and removed, the simulated canals were irrigated with $2 \mathrm{~mL}$ of $2.5 \% \mathrm{NaOCl}$ solution (Rio Química, São José do Rio Preto, SP, Brazil), with a plastic syringe and 29-G NaviTip (Ultradent, South Jordan, UT, USA). All the previously described procedures were performed by a single operator, a specialist in endodontics.

Each instrument was used to prepare a simulated canal, right after being removed from the packaging material. Subsequently, the instrument was reused another two times, totaling the preparation of three different simulated canals. Whenever a simulated canal preparation was concluded, the instrument was submitted in a thermochemical cleaning process in an ultrasonic bath (Cristófoli, Campo Mourão, PR, Brazil), using water/ enzymatic detergent in the dilution of $5 \mathrm{~mL}$ per liter of distilled water, at $65^{\circ} \mathrm{C}$. After the first and third preparation performed with each instrument, they were sent to SEM equipment for analysis of their topography, according to the protocol described in the initial analysis.

Topographic analysis of the instruments surface was performed by the examiners at the same angle of the active part of the instruments, comparing the images obtained before and after their use. The following features on the active part of each instrument were considered in the analysis: irregular edges, grooves, microcavities and burrs (3). A scoring system similar to that used by Troian et al. (8) was adopted to classify the topographic changes in the instruments: 1 - long axis of the instrument without any defect or deformation on the examined surface; 2 - long axis of the instrument with approximately one to three areas with defects or deformations on the examined surface; 3 - long axis of the instrument with approximately four to five areas with defects or deformations on the 
examined surface; 4 - long axis of the instrument with over 5 areas with defects or deformations on the examined surface.

Chemical analysis of the NiTi content (wt \%) on the instruments surface after the first and third use was also performed, according to the protocol described in the analysis of instruments by EDS before use.

\section{Statistical Analysis}

Initially, the data obtained were submitted to the normality test (Kolmogorov \& Smirnov test). For the topographic changes in the instruments, the KruskalWallis test $(p<0.05)$ was performed. For the $\mathrm{Ni}$ and $\mathrm{Ti}$ content on instruments surface, the obtained values were statistically analyzed using 1-way ANOVA and Tukey test $(p<0.05)$. Statistical tests were performed using the BioEstat 5.0 program (BioEstat Software, Belém, PA, Brazil).

\section{Results}

\section{Analysis of Defects and Deformations on Instruments Surfaces (SEM)}

Representative SEM micrographs of the active part of the instruments are in Figure 1.

The incidence of defects and deformations (irregular edges, grooves, microcavities and burrs) observed on the instruments surface before and after the first and third use is in Table 1.

There were defects and deformations in all instruments, before and after reuse. On the surface of the new instruments were noted several perpendicular marks along their long axis, characteristic of the machining process (Fig. $1 A, F$ and J). The perpendicular marks remained on the instruments surface after the third use, but they were less accentuated, because of instruments wear (Fig. 1I). there were also several deformities on the cutting blades of the instruments after reuse, mainly in PNX2 and WO Groups (Fig. 1k), compared with the unused instruments.

When each type of defect was compared isolated, and in the same portion of the active part of the instrument, no significant difference was observed among groups, irrespective of the time interval of analysis $(p>0.05)$.

The results of the topographic changes in the instruments, considering the adopted score, are in Figure 2A. Only the instruments of WO Group presented a significant increase in the quantity of defects and deformations, at $4 \mathrm{~mm}$ short of the active tip and after the third use $(p<0.05)$. Between PNX1 and PNX2 Groups, irrespective of the portion of the active part of the instrument and time interval of analysis, there was no statistically significant difference ( $p>0.05)$.

\section{Quantitative Analysis of Ni and Ti (EDS)}

The mean values (wt \%) of $\mathrm{Ni}$ and $\mathrm{Ti}$ content on the instruments surface are in Figures $2 \mathrm{~B}$ and $2 \mathrm{C}$. The instruments of PNX1 Group had significant decrease in Ni content only after the third use, compared with the unused instruments $(p<0.05)$. PNX2 Group had a significant decrease in $\mathrm{Ni}$ content in the different time intervals of analysis $(p<0.05)$. The same could occurred in the instruments of WO Group $(p<0.05)$.

Regarding Ti content, the instruments of PNX1 Group had no significant decrease throughout use ( $p>0.05)$. However, in PNX2 Group, there was a significant decrease in Ti content before continuous use $(p<0.05)$. In WO Group, significant decrease of Ti content was noted before first and third use, in comparison with the unused instruments $(p<0.05)$. There was no significant difference between the first and third use ( $p>0.05)$.

Table 1. Incidence of defects and deformations on instruments surface before and after use

\begin{tabular}{|c|c|c|c|c|c|c|c|c|c|c|c|c|}
\hline \multirow{2}{*}{ Instruments } & \multicolumn{3}{|c|}{ Irregular edges } & \multicolumn{3}{|c|}{ Grooves } & \multicolumn{3}{|c|}{ Microcavities } & \multicolumn{3}{|c|}{ Burrs } \\
\hline & Tip & $2 \mathrm{~mm}$ & $4 \mathrm{~mm}$ & Tip & $2 \mathrm{~mm}$ & $4 \mathrm{~mm}$ & Tip & $2 \mathrm{~mm}$ & $4 \mathrm{~mm}$ & Tip & $2 \mathrm{~mm}$ & $4 \mathrm{~mm}$ \\
\hline PNX1 (Before use) & 4 & 10 & 10 & 2 & 9 & 5 & 0 & 2 & 1 & 1 & 10 & 10 \\
\hline PNX2 (Before use) & 9 & 10 & 10 & 3 & 8 & 8 & 1 & 0 & 0 & 0 & 10 & 10 \\
\hline WO (Before use) & 9 & 10 & 10 & 4 & 7 & 8 & 0 & 0 & 0 & 2 & 10 & 10 \\
\hline PNX1 (After 1st use) & 5 & 10 & 10 & 4 & 8 & 8 & 0 & 0 & 0 & 1 & 10 & 10 \\
\hline PNX2 (After 1st use) & 9 & 10 & 10 & 10 & 9 & 8 & 2 & 0 & 0 & 3 & 10 & 10 \\
\hline WO (After 1st use) & 10 & 10 & 10 & 8 & 9 & 8 & 1 & 1 & 2 & 5 & 10 & 10 \\
\hline PNX1 (After 3rd use) & 6 & 10 & 10 & 5 & 9 & 9 & 0 & 0 & 0 & 4 & 10 & 10 \\
\hline PNX2 (After 3rd use) & 10 & 10 & 10 & 10 & 9 & 8 & 1 & 0 & 0 & 7 & 10 & 10 \\
\hline WO (After 3rd use) & 10 & 10 & 10 & 9 & 10 & 9 & 1 & 0 & 2 & 7 & 9 & 8 \\
\hline
\end{tabular}

There was no statistically significant difference among groups (level of significance=5\%). Kruskal-Wallis test, $p<0.05$. $n=10$. 


\section{Discussion}

The systems tested in the present study were included instruments meant for single use or limited to the preparation of a maximum of 3 or 4 canals, according to their manufacturers. As they are manufactured of M-Wire alloy, the clinical reuse of these instruments must be
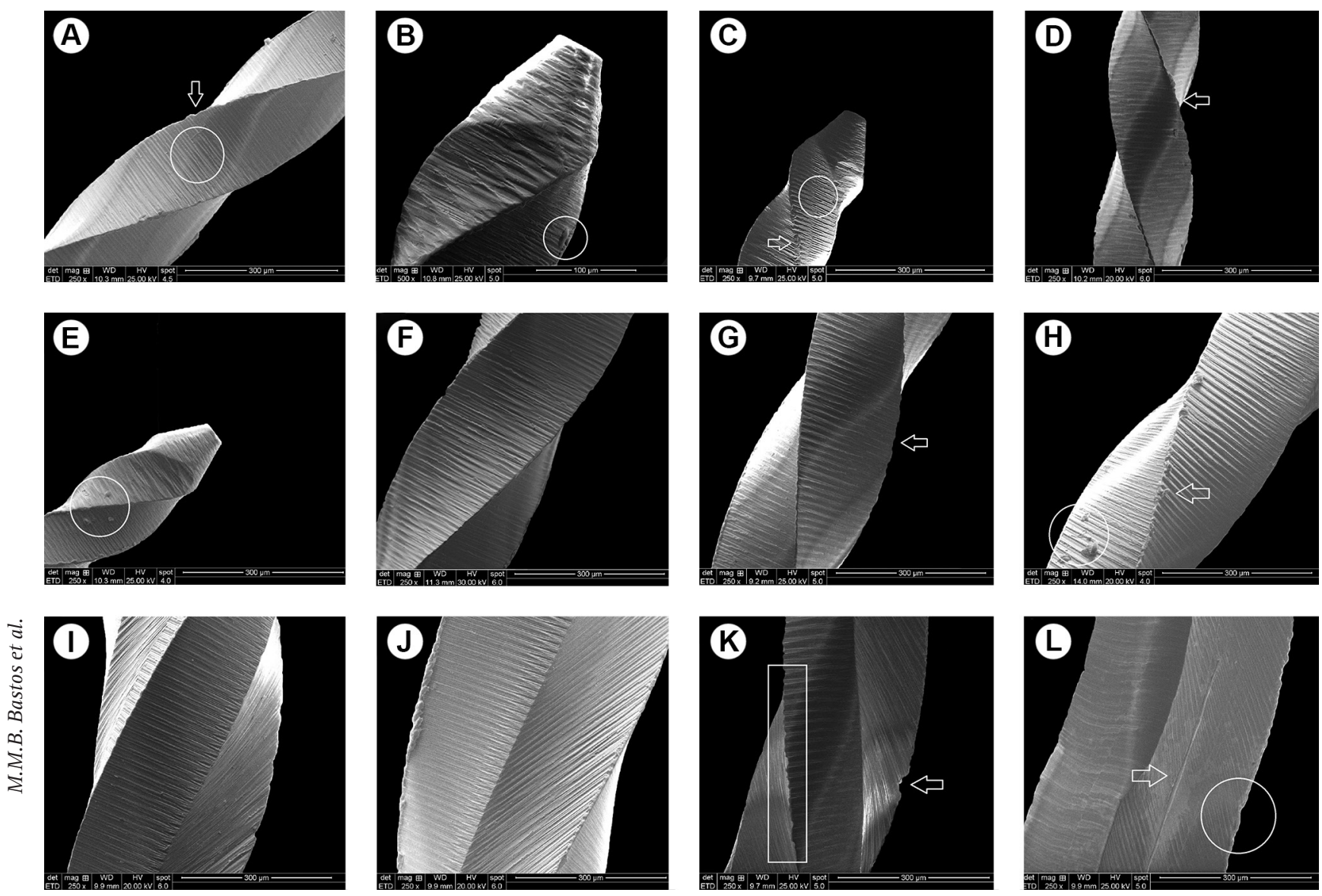

Figure 1. Representative SEM micrographs of the instruments surface before and after use. PNX1 Group (before use). (a) Perpendicular marks of the machining process (circle). Irregular edges on the cutting blades (arrow). Original magnification, $\times 250$. (b) Higher magnification of active tip showing details of defects on instrument surface (circle). Original magnification, $\times 500$. PNX1 Group (after third use). (c) Marks of the machining process on active tip surface (circle). Burs on the instrument cutting blades (arrow). Original magnification, $\times 250$. (d) Irregular margin on the cutting blades (arrow). Original magnification, $\times 250$. PNX2 Group (before use). (e) Defects on surface of the active tip (circle). (box). Original magnification, $\times 250$. (f) Marks of machining process and irregular edges on cutting blades. Original magnification, $\times 250$. PNX2 Group (after third use). (g) Edges with more accentuated irregularities (arrow). Original magnification, $\times 250$. (h) Burs (arrow) and topographic defects (circle). Original magnification, $\times 250$. W0 Group (before use). (i) and (j) Perpendicular marks and a few irregularities on cutting blades. Original magnification, $\times 250$. W0 Group (after third use). (k) Irregularities on cutting blades (box and arrow). Original magnification, $\times 250$. (l) Irregular edges (circle) and large groove on instrument surface (arrow). Machining process marks on the instrument were less accentuated. Original magnification, $\times 250$.
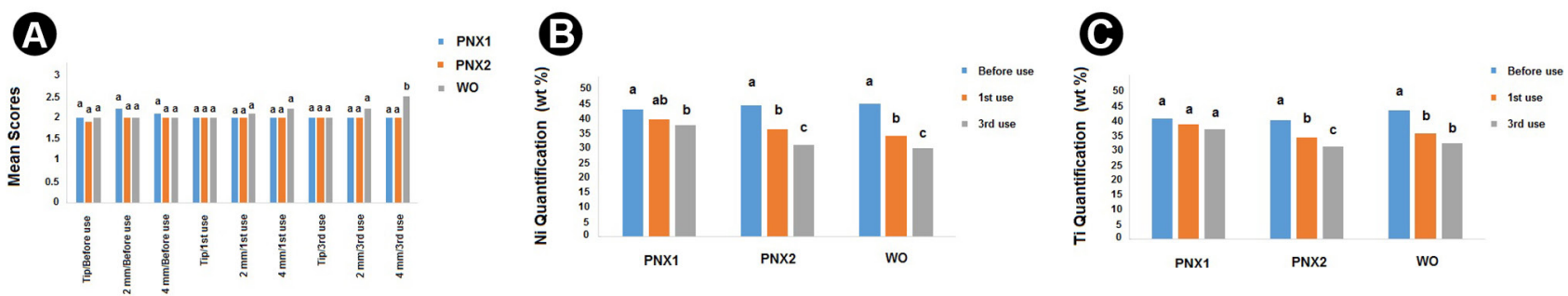

Figure 2. Mean scores of defects and deformations; and mean values of $\mathrm{Ni}$ and Ti quantification before and after instruments use. (a) Graphic representation of mean scores of the defects and deformations observed in the instruments (Kruskal-Wallis test, $\mathrm{p}<0.05)$. (b) Graphic representation of mean Ni quantification values. (c) Graphic representation of mean Ti quantification values (1-way ANOVA, Tukey test, $p<0.05$ ).

* Different lowercase letters over bars indicate statistically significant difference. 
avoided, thereby, diminishing deterioration of the metal alloy, and consequently, the risk of an unexpected fracture of the instrument during use $(3,7,9)$.

Several studies evaluated the cyclic fatigue resistance of reciprocating instruments. Burklein et al. (10) demonstrated that reciprocating instruments may be safely used for the preparation of at least 4 root canals. On the other hand, Park et al. (11) and Caballero et al. (12) reported that these instruments withstand the preparation of 5 to 9 root canals without presenting deformities. Due to the controversial results, these findings must be evaluated with precaution, because even if they do not fracture, such instruments may undergo mechanical deformations that reduce their efficiency during biomechanical preparation $(3,4)$.

In the present study, topographic analysis of instruments surface was performed by SEM. Several studies have reported the accuracy of this method at evaluating changes in the morphological characteristics of metallic materials, such as endodontic instruments $(3,7,13-16)$.

Although the instruments used in this research were brand new, different defects on their surfaces were found even before use. The process of instruments machining leads to concentration of debris (metal particles) on their surfaces, in addition to other forms of defects (3). Chianello et al. (17) reported that no NiTi instrument was free of topographic irregularities, and most presented between 2 to 7 defects on the surface even before use, corroborating the findings of this study. Nevertheless, it must be emphasized that the presence of these defects on instruments before use, may lead to greater surface deterioration when they are put into action (14). Therefore, the authors believe that manufacturers should propose improvements in the machining process, with the purpose of reducing the defects on instruments surface.

Considering the scoring system adopted in this study, only the Primary 25.08 instruments (WO Group) had significant increase $(p<0.05)$ in the quantity of defects and deformations after use. However, this increase occurred only after the third use, and at $4 \mathrm{~mm}$ from the active tip of the instrument. Among the other groups, irrespective of the portion of the active part and the number of times the instrument was used, no significant morphological changes ( $p>0.05$ ) were observed on the surface of cutting blades. This result agrees with the studies of Pedullà et al. (18) and Plotino et al. (19), who demonstrated that among the instruments manufactured of M-Wire alloy, those of the WaveOne system had the greatest limitations of their physical properties, particularly as regards to cyclic fatigue resistance. Furthermore, the authors point out that the cross section and asymmetrical rotational axis of the ProTaper Next instruments allow less contact with the root canal walls during preparation, differently from the WaveOne system (19). Caper et al. (20) reported that ProTaper Next was associated with less debris extrusion compared with other rotary NiTi instruments, while Kim et al. (21) found that the design of WaveOne instruments produced a longer contact of the cutting blades with dentin, causing greater wear of their surface.

Grooves were observed on all the instruments of the tested systems, irrespective of the time interval of analysis (before and after use), with higher frequency at 2 and 4 $\mathrm{mm}$ short of the active tip. According to Hanan et al. (3), grooves on the cutting blade of instrument may function as points of stress concentration, leading to premature failure. Despite this, none of the instruments evaluated in this study presented fracture after their constant use, differing from the findings of Kim et al. (21), but corroborating the results of Hanan et al. (3). Microcavities were also detected in all instruments before and after continuous use. The microcavities after use may be associated with loss of $\mathrm{Ni}$ and $\mathrm{Ti}$ atoms (22). The chemical composition and geometry of NiTi alloys has a binary intermetallic and equiatomic bonding force between $\mathrm{Ni}$ and $\mathrm{Ti}$ (22), which may be changed by a thermodynamic process, or/and when submitted to certain stress, as root canal preparation (23).

Analysis of chemical composition demonstrated the presence of spectral lines of $\mathrm{Ni}, \mathrm{Ti}, \mathrm{O}, \mathrm{C}$ and $\mathrm{Al}$. According to the manufacturers, ProTaper Next and WaveOne instruments do not contain Al in their composition. For this reason, the authors speculated that the presence of this element must have been due to contamination of instruments, since the metal stubs of the SEM equipment are made in Al.

Regarding the other detected elements, the authors decided present data for $\mathrm{Ni}$ and $\mathrm{Ti}$ only, as $\mathrm{O}$ and $\mathrm{C}$ are present only in the superficial passivating layer of protection that covers the instruments (22). The NiTi alloy surface is largely composed of titanium oxide $\left(\mathrm{TiO}_{2}\right)$, and lower quantities of nickel oxide $(\mathrm{NiO})$ and metallic nickel $\left(\mathrm{Ni}_{2} \mathrm{O}_{3}\right)$ (22). The oxide layer thickness ranges between 2-20 $\mathrm{nm}$, depending on the method of alloy preparation (22). This oxide layer plays an important role, as it prevents the NiTi of the internal layer from undergoing wear and corrosion $(22,24)$. Therefore, it is worth pointing out that the presence of $\mathrm{O}$ and $\mathrm{C}$ is frequently related to non-treatment of the oxide layer, reducing the mechanical strength of the alloy, which may compromise the performance of the instruments $(22,24)$.

Despite Kalyoncuoğlu et al. (25) reporting alterations in NiTi content of instruments before and after use, this change was not significant. On the other hand, the results of the present study demonstrated a significant decrease of $\mathrm{Ni}$ content $(p<0.05)$ on instruments surface, irrespective of the tested system, before and after the first and third use. However, only the instrument X2 (ProTaper Next) had 
significant decrease $(p<0.05)$ of Ti content in the different time intervals of analysis.

As the oxide layer of the tested instruments is composed of titanium oxide, nickel oxide and metallic nickel, the decrease in NiTi content detected in this study may be limited to the instruments' surface. Ni and Ti are chemically bonded by a strong intermetallic bond (20 to $200 \mathrm{Kcal} /$ mol) (22). However, gradual deformation by repeated use of the instrument destroys the oxide layer, exposing the NiTi alloy to a process of corrosion, which weakened the intermetallic bond, and made easier the loss of electrons from $\mathrm{Ni}$ by oxidation $\left(\mathrm{Ni}+2 \mathrm{e}-\leftrightarrow^{+2}-0.24 \mathrm{~V}\right)$ than $\mathrm{Ti}(\mathrm{Ti}+$ $2 \mathrm{e}-\leftrightarrow^{+2} 1.63 \mathrm{~V}$ ) (22). Otsuka \&t Ren (22) affirmed that Ni dissolves more easily than $\mathrm{Ti}$, since the oxides of which it was composed, ${ }_{28} \mathrm{Ni}[\mathrm{Ar}] 3 \mathrm{~d}^{8} 4 \mathrm{~s}^{2}$, were less stable than those of $\mathrm{Ti}_{1} \mathrm{TiO}_{2}[\mathrm{Ar}] 3 \mathrm{~d}^{2} 4 \mathrm{~s}^{2}$.

SEM images revealed the presence of defects and deformations on the surface of the tested instruments even before use. However, continuous reuse produced increase of defects and deformations only for WaveOne system, after the third use. EDS analysis demonstrated that reuse led to significant changes in $\mathrm{Ni}$ and $\mathrm{Ti}$ content on instruments surface.

\section{Resumo}

Este estudo teve como objetivo avaliar as alterações nas características de superfície e teor de NiTi de instrumentos reciprocantes e rotatórios após uso contínuo. Trinta instrumentos novos foram separados em três grupos $(n=10)$ : Grupo PNX1 - ProTaper Next system - instrumento X1; Grupo PNX2 - ProTaper Next system - instrumento X2 e Grupo WO - WaveOne system - instrumento Primary 25.08. Os instrumentos foram utilizados para o preparo de 60 canais radiculares simulados. Análise por microscopia eletronica de varredura (MEV), a análise química do conteúdo de Ni e Ti por espectroscopia de energia dispersiva (EED) foram realizadas antes e após o primeiro e terceiro uso dos instrumentos. Apenas o Grupo WO apresentou aumento significativo na quantidade de defeitos e deformações após o terceiro uso $(p<0,05)$. 0 grupo PNX1 teve diminuição significativa no teor de Ni após o terceiro uso, em comparação aos instrumentos não utilizados $(p<0,05)$. 0 grupo PNX1 não apresentou diminuição do teor de Ti ao longo do tempo de uso $(p>0,05)$, no entanto, no Grupo PNX2, houve diminuição significativa nos diferentes intervalos de tempo de análise $(p<0,05)$. 0 uso contínuo promoveu aumento nos defeitos e deformações somente para os instrumentos WaveOne. A composição quimica apresentou alterações significativas de acordo com o tempo de uso dos instrumentos.

\section{References}

1. Bürklein $S$, Tsotsis $P$, Schäfer E. Incidence of dentinal defects after root canal preparation: reciprocating versus rotary instrumentation. J Endod 2013;39:501-504.

2. Gambarini G, Gergi R, Naaman A, Osta N, Al Sudani D. Cyclic fatigue analysis of twisted file rotary NiTi instruments used in reciprocating motion. Int Endod J 2012;45:802-806.

3. Hanan $A R$, Meireles DA, Sponchiado Júnior EC, Hanan $S$, Kuga $M C$, Bonetti Filho I. Surface characteristics of reciprocating instruments before and after use--a SEM analysis. Braz Dent J 2015;26:121-127.

4. da Frota MF, Espir CG, Berbert FL, Marques AA, Sponchiado-Junior EC, Tanomaru-Filho $\mathrm{M}$, et al.. Comparison of cyclic fatigue and torsional resistance in reciprocating single-file systems and continuous rotary instrumentation systems. J Oral Sci 2014;56:269-275.
5. Capar ID, Ertas H, Arslan H. Comparison of cyclic fatigue resistance of novel nickel-titanium rotary instruments. Aust Endod J 2015;41:24-28.

6. Yared G. Canal preparation using only one Ni-Ti rotary instrument: preliminary observations. Int Endod J 2008;41:339-344.

7. Arantes WB, da Silva CM, Lage-Marques JL, Habitante S, da Rosa LC, de Medeiros JM. SEM analysis of defects and wear on Ni-Ti rotary instruments. Scanning 2014;36:411-418.

8. Troian $\mathrm{CH}$, Só MVR, Figueiredo JAP, Oliveira EPM. Deformation and fracture of RaCe and $\mathrm{K} 3$ endodontic instruments according to the number of uses. Int Endod J 2006;39:616-625.

9. Al-Hadlaq SMS, Al Jarbou FA, Al Thumairy RI. Evaluation of cyclic flexural fatigue of M-Wire nickel-titanium rotary instruments. J Endod 2010;36:305-307.

10. Burklein $S$, Hinschitza $K$, Dammaschke T, Schäfer E. Shaping ability and cleaning effectiveness of two single-file systems in severely curved root canals of extracted teeth: Reciproc and WaveOne versus Mtwo and Protaper. Int Endod J 2012;45:449-461.

11. Park SK, Kim YJ, Shon WJ, You SY, Moon YM, Kim HC, et al.. Clinical efficiency and reusability of the reciprocating nickel-titanium instruments according to the root canal anatomy. Scanning 2014;36:246-251.

12. Caballero H, Rivera F, Salas H. Scanning electron microscopy of superficial defects in twisted files and Reciproc nickel-titanium files after use in extracted molars. Int Endod J 2015;48:229-235.

13. Gavini G, Caldeira CL, Akisue E, Candeiro GTM, Kawakami DAS. Resistance to flexural fatigue of Reciproc R25 files under continuous rotation and reciprocating movement. J Endod 2012;38:684-687.

14. Pirani C, Paolucci A, Ruggeri O, Bossù M, Polimeni A, Gatto MR, et al.. Wear and metallographic analysis of WaveOne and Reciproc NiTi instruments before and after three uses in root canals. Scanning 2014;36:517-525.

15. Nygren $H$, llver $L$, Malmberg P. Mineralization at titanium surfaces is a two-step process. J Funct Biomater 2016;15:7(1).

16. Prati C, Zamparini F, Scialabba VS, Gatto MR, Piattelli A, Montebugnoli L, et al.. A 3-year prospective cohort study on 132 calcium phosphateblasted implants: flap vs flapless technique. Int J Oral Maxillofac Implants 2016;31:413-423.

17. Chianello G, Specian VL, Hardt LC, Raldi DP, Lage-Marques JL, Habitante SM. Surface finishing of unused rotary endodontic instruments: a SEM study. Braz Dent J 2008;19:109-113.

18. Pedullà E, Grande NM, Plotino G, Gambarini G, Rapisarda E. Influence of continuous or reciprocating motion on cyclic fatigue resistance of 4 different nickel-titanium rotary instruments. J Endod 2013;39:258-261.

19. Plotino G, Grande NM, Porciani PF. Deformation and fracture incidence of Reciproc instruments: a clinical evaluation. Int Endod J 2015;48:199205.

20. Capar ID, Arlan H, Akcay M, Ertas H. An in vitro comparison of apically extruded debris and instrumentation times with ProTaper Universal, ProTaper Next, Twisted File Adaptive, and HyFlex instruments. J Endod 2014;40:1638-1641.

21. Kim HC, Kim HJ, Lee CJ, Kim BM, Park JK, Versluis A. Mechanical response of nickel titanium instruments with different cross-sectional designs during shaping of simulated curved canals. Int Endod J 2009;42:593602.

22. Otsuka K, Ren X. Physical metallurgy of Ti-Ni based shape memory alloys. Prog Mater Sci 2005;50:511-678.

23. Yamazaki-Arasaki A, Cabrales R, Dos Santos M, Kleine B, Prokopowitsch I. Topography of four different endodontic rotary systems, before and after being used for the 12th time. Microsc Res Tech 2012;75:97-102.

24. Fatma Y, Ozgur U. Evaluation of surface topography changes in three NiTi file systems using rotary and reciprocal motion: An atomic force microscopy study. Microsc Res Tech 2014;77:177-182.

25. Kalyoncuoğlu E, Keskin C, Uzun İ, Bengü AS, Guler B. Scanning electron microscopy with energy dispersive $\mathrm{X}$-ray spectrophotometry analysis of reciprocating and continuous rotary nickel-titanium instruments following root canal retreatment. J Oral Sci 2016;58:401-406.

Received February 8, 2017 Accepted April 26, 2017 